
Revue canadienne de chimie

\title{
Common bed bugs can biosynthesize pheromone components from amino acid precursors in human blood
}

\begin{tabular}{|c|c|}
\hline Journal: & Canadian Journal of Chemistry \\
\hline Manuscript ID & cjc-2017-0407.R1 \\
\hline Manuscript Type: & Article \\
\hline Date Submitted by the Author: & 11-Sep-2017 \\
\hline Complete List of Authors: & $\begin{array}{l}\text { Gries, Regine; Simon Fraser University Department of Biological Sciences, } \\
\text { Biological Sciences } \\
\text { Zhai, Huimin; Simon Fraser University, Chemistry } \\
\text { Lewis, Andrew; Simon Fraser University, Chemistry } \\
\text { Britton, Robert; Simon Fraser University, Chemistry } \\
\text { Gries, Gerhard; Simon Fraser University Department of Biological Sciences, } \\
\text { Biological Sciences }\end{array}$ \\
\hline $\begin{array}{r}\text { Is the invited manuscript for } \\
\text { consideration in a Special } \\
\text { Issue?: }\end{array}$ & SFU \\
\hline Keyword: & $\begin{array}{l}\text { pheromone biosynthesis, L-methionine, histidine, histamine, dimethyl } \\
\text { trisulfide }\end{array}$ \\
\hline
\end{tabular}


Common bed bugs can biosynthesize pheromone components from amino acid precursors in human blood

Regine Gries, Huimin Zhai, Andrew R. Lewis, Robert Britton and Gerhard Gries

Regine Gries, Gerhard Gries. Department of Biological Sciences, Simon Fraser University, Burnaby, British Columbia, V5A 1S6 Canada. Corresponding author: Gerhard Gries (email: gries@sfu.ca).

Huimin Zhai, Andrew Lewis, Robert Britton. Chemistry Department, Simon Fraser University, Burnaby, British Columbia, V5A 1S6 Canada. 


\begin{abstract}
We have recently shown that the aggregation pheromone of the common bed bug, Cimex lectularius, comprises a six-component blend of dimethyl disulfide (DMDS), dimethyl trisulfide (DMTS), (E)-2-hexenal, $(E)$-2-octenal, 2-hexanone and histamine. Here we tested the hypothesis that bed bugs biosynthesize some pheromone components from amino acid precursors in human blood, namely DMDS and DMTS from L-methionine and histamine from histidine. We tested this hypothesis by $(i)$ allowing bed bugs to feed on and metabolize sheep blood enriched with ${ }^{13} \mathrm{C}$-labelled histidine or ${ }^{2} \mathrm{H}$-labelled methionine, (ii) extracting bed bug feces (a source of the aggregation pheromone), and (iii) analyzing feces extracts by GC-MS, HPLC-MS and NMR. The analyses revealed that bed bugs converted ${ }^{2} \mathrm{H}-$ methionine to ${ }^{2} \mathrm{H}-$ DMDS and ${ }^{2} \mathrm{H}$-DMTS, and ${ }^{13} \mathrm{C}$-histidine to ${ }^{13} \mathrm{C}$-histamine. There is not enough histidine in human blood to account for the amount of histamine that bed bugs produce and excrete with their feces, and only a small proportion of the available ${ }^{13} \mathrm{C}$-histidine was converted to ${ }^{13} \mathrm{C}$-histamine in our study. Therefore, it is likely that bed bugs biosynthesize histamine, and possibly also DMDS and DMTS, primarily de novo.
\end{abstract}

Key words: pheromone biosynthesis, L-methionine, histidine, histamine, dimethyl disulfide, dimethyl trisulfide 


\section{Introduction}

Over the last two decades, common bed bugs, Cimex lectularius (Hemiptera: Cimicidae), have become a global epidemic. ${ }^{1}$ Bed bug infestations have multiple adverse effects on the human host, causing insomnia, paranoia, emotional distress, and diverse dermal reactions. ${ }^{1-4}$ Thus, rapid detection and eradication of bed bug infestations is paramount. As the aggregation pheromone of bed bugs could be used as an effective and affordable trap lure to detect bed bug infestations, intense research was undertaken to identify this pheromone. It comprises five volatile components [dimethyl disulfide (DMDS), dimethyl trisulfide (DMTS), (E)-2-hexenal, (E)-2octenal, 2-hexanone] which attract bed bugs to a harborage, and one less-volatile component (histamine) which causes their arrestment upon contact. ${ }^{5}$

The origin or biosynthesis of these pheromone components is still not known. It seemed plausible that bed bugs simply acquire histamine from the immunological response of fed-on human hosts. Yet, human blood withdrawn from bed bugs just after their blood meal contained no histamine. ${ }^{5}$ It follows that bed bugs biosynthesize histamine and other pheromone components de novo, or that they convert biosynthetic precursors present in human blood into pheromone components. For example, the amino acids histidine and methionine are both present in human blood ${ }^{6}$ and could serve as biosynthetic precursors for histamine as well as DMDS and DMTS, respectively.

Decarboxylation of histidine (via a histidine decarboxylase) has been shown in humans, ${ }^{7}$ insects $^{8}$ and bacteria. ${ }^{9}$ The metabolism of methionine has received less attention but there is evidence that the ant Paltothyreus tarsatus can produce its pheromone components DMDS and DMTS from radiolabelled methionine..$^{10,11}$ 
Here we tested the hypothesis that bed bugs can produce histamine from histidine, and DMDS and DMTS from methionine. We tested this hypothesis by allowing bed bugs to feed on sheep blood enriched with isotopically fully-labelled ${ }^{13} \mathrm{C}$-histidine $\left({ }^{13} \mathrm{C}_{6}\right.$-histidine) or ${ }^{2} \mathrm{H}_{3}$-methionine and by analyzing bed bug feces (a source of the aggregation pheromone) for the presence of ${ }^{13} \mathrm{C}$ histamine, ${ }^{2} \mathrm{H}$-DMDS and ${ }^{2} \mathrm{H}$-DMTS.

\section{Methods}

\section{Experimental insects}

A colony of about 4,000 bed bugs was kept in the insectary of Simon Fraser University at a temperature of $\sim 24^{\circ} \mathrm{C}$, ambient relative humidity and a photoperiod of $14 \mathrm{~h}$ light to $10 \mathrm{~h}$ dark ${ }^{5}$. About 150 bed bugs were confined in each of $2750-\mathrm{mL}$ jars fitted with both a square of cardboard $(2 \times 2 \mathrm{~cm})$ at the bottom and a strip of cardboard $(2 \times 4 \mathrm{~cm})$ diagonally across the jar. Bed bugs in each jar were allowed to feed every four weeks. For feeding, jars were covered with fine mesh, inverted and pressed against R.G.'s forearm so that the bed bugs could feed through the mesh.

\section{Feeding of bed bugs on sheep blood enriched with ${ }^{2} \mathrm{H}$-methionine or $\mathrm{C}^{13}$-histidine}

To test whether bed bugs can biosynthesize DMDS and DMTS from methionine, and histamine from histidine, they were allowed to feed through an artificial membrane ${ }^{12}$ on defibrinated sheep blood (5 or $10 \mathrm{~mL}$, Hemo Stat Laboratories, Dixon, CA, 95620 USA, distributed in Canada by Cedarlane Laboratories, Burlington ON, L7L 5R2) enriched with either ${ }^{2} \mathrm{H}$-labelled methionine (0.25 or $2.5 \mathrm{mg}$ ) (Methyl-D3, 98\% isotopic enrichment; Cambridge Isotope Laboratories Inc., Andover, MA 01810, USA) or ${ }^{13} \mathrm{C}$-labelled histidine (5 mg) (U-13C6, 97-99\% isotopic 
enrichment; Cambridge Isotope Laboratories Inc.) (Fig. 1; Table 1). Sheep blood, and sheep blood enriched with $2.5 \mathrm{mg}$ of methionine [Sigma-Aldrich 98\% (chemical purity) HPLC; SigmaAldrich Co., St. Louis, MO 63103, USA) or $5 \mathrm{mg}$ of histidine $\mathrm{HCl}: \mathrm{H}_{2} \mathrm{O}$ (L-Histidine mono hydrochloride monohydrate $>98 \%$ (chemical purity) TLC; Sigma-Aldrich] served as controls (Table 1).

In each replicate, 100 or 200 bed bugs were allowed to blood-feed for 2.5 h. To increase the amount of analyte in replicates 8 and 9, three separate groups of 200 bed bugs each were allowed to feed consecutively on the same blood source, for a total of 600 bed bugs per replicate. In each replicate, all bed bugs that had consumed at least some blood (Table 1) were transferred into a clean $100-\mathrm{mL}$ vial $(6.5 \mathrm{~cm} \times 5.5 \mathrm{~cm})$, lined with a filter paper disc $(4 \mathrm{~cm}$ diam, Whatman \#1) and fitted with another piece of filter paper $(4 \times 7 \mathrm{~cm})$ folded 4 times. Bed bugs were kept in these jars for four weeks during which they digested the blood and defecated on the filter paper.

\section{GC-MS, HPLC-MS and NMR analyses of feces-soiled filter paper}

For analyses of the volatile pheromone components DMDS and DMTS, the methodology applied was similar to that previously described. ${ }^{5}$ Briefly, feces-soiled filter paper was cut into $5 \times 5 \mathrm{~mm}$ pieces and placed into a $20-\mathrm{mL}$ headspace vial which was sealed with a $20-\mathrm{mm}$ (OD) white silicone septum and a 20-mm crimp cap. This vial was then introduced into the oven of a Headspace Sampler (Agilent 7694) kept at $90^{\circ} \mathrm{C}$. After $30 \mathrm{~min}$, headspace volatiles in the vial were withdrawn with an automated syringe and directly injected into the carrier gas flow entering a Varian Saturn 2000 Ion Trap gas chromatograph-mass spectrometer (GC-MS) fitted with a DB-5 MS column (30 $\mathrm{m} \times 0.25 \mathrm{~mm}$ ID). Samples were analyzed using the following temperature program: $50^{\circ} \mathrm{C}$ for $5 \mathrm{~min}$, then $10^{\circ} \mathrm{C}$ per min to $280^{\circ} \mathrm{C}$. 
For analyses of the non-volatile pheromone component histamine, samples were also processed as previously reported. ${ }^{5}$ Briefly, feces-soiled filter paper was cut into small pieces $(5 \times$ $5 \mathrm{~cm}$ ) and extracted consecutively in hexanes, dichloromethane, acetonitrile and methanol $(\mathrm{MeOH})$ using 5-10 $\mathrm{mL}$ of each organic solvent. The $\mathrm{MeOH}$ extract containing histamine was then concentrated to $600 \mu \mathrm{L}$, and a $20-\mu \mathrm{L}$ aliquot was subjected to analysis by high-performance liquid chromatography-mass spectrometry (HPLC-MS). The remainder $(580 \mu \mathrm{L})$ of the $\mathrm{MeOH}$ extract was evaporated to dryness and $\mathrm{CD}_{3} \mathrm{OD}$ was added for NMR analyses.

For HPLC-MS analyses of samples, an Agilent 1200 HPLC coupled to a Bruker MaXis Impact Ultra-High Resolution Tandem TOF (UHR-Oq-TOF) MS was equipped with an Agilent Zorbax RX-Sil column $(150 \mathrm{~mm} \times 2.1 \mathrm{~mm}, 5 \mu \mathrm{m}$ particle size $)$. The column was set to $30^{\circ} \mathrm{C}$ and eluted with an isocratic flow $(0.3 \mathrm{~mL} / \mathrm{min})$ of acetonitrile/water $(60 / 40)$ containing $0.1 \%$ formic acid. For positive electrospray ionization mass spectrometry, the gas temperature and flow were set to $200^{\circ} \mathrm{C}$ and to $9 \mathrm{~mL} / \mathrm{min}$, respectively, the nebulizer was set to 2 bar, and the capillary voltage to $4000 \mathrm{~V}$.

For NMR spectroscopic analyses, $180-\mu \mathrm{L}$ aliquots of extract samples (methanol-D4; Cambridge Isotope Laboratory) were added to a 3-mm (outer diameter) MATCH NMR tube. ${ }^{13} \mathrm{C}$ NMR spectra were acquired using a $10.5-\mu \mathrm{s}, 90$-degree pulse at $298 \mathrm{~K}$ with power-gated WALTZ16 composite pulse decoupling of $1 \mathrm{H}$ on a Bruker AVANCE II 600 spectrometer equipped with a Bruker 5-mm QNP cryoprobe operated at $150.92 \mathrm{MHz}$ for ${ }^{13} \mathrm{C}$. A spectral width of $250 \mathrm{ppm}$ was used with a recycle delay (D1) of $2 \mathrm{~s}$ and an acquisition time of $1.74 \mathrm{~s}(131,072$ complex data points). For analyses of bed bug feces extract samples, 20,000 transients were summed (experimental time $21 \mathrm{~h}$ ), and the chemical shift scale was calibrated by setting the residual solvent peak to 49.0 ppm. MNova (ver. 11, Mestrelab Research, S.L.) peak fitting mode 
was used to deconvolute the spectra using mixed Lorentzian-Gaussian peak shapes to accurately measure the peak areas because of the presence of other overlapping resonances close to the peaks of interest (Fig. 3-b).

\section{Results}

When groups $(n=9)$ of bed bugs were offered to feed on sheep blood, or sheep blood enriched with either ${ }^{2} \mathrm{H}$-methionine or methionine, or ${ }^{13} \mathrm{C}$-histadine or histadine, $25-96 \%$ of insects ingested at least some blood (Table 1).

Bed bugs ingesting and metabolizing sheep blood enriched with ${ }^{2} \mathrm{H}_{3}$-methionine produced both ${ }^{2} \mathrm{H}_{3}$ - and ${ }^{2} \mathrm{H}_{6}$-DMDS as well as ${ }^{2} \mathrm{H}_{3}$ - and ${ }^{2} \mathrm{H}_{6}$-DMTS (Table 2, replicates 3-5); expectedly, control groups of bed bugs metabolizing sheep blood lacking ${ }^{2} \mathrm{H}_{3}$-methionine produced exclusively DMDS and DMTS (Table 2; replicates 1-2).

In total ion chromatograms of fecal bed bug odorants, DMDS and DMTS eluted in two well resolved peaks at 5.4 and 9.4 min, respectively. When bed bugs had ingested sheep blood enriched with ${ }^{2} \mathrm{H}_{3}$-methionine, each of the two peaks contained both deuterated and protonated pheromone components. Earlier scans of the DMDS peak revealed mainly fragment ions indicative of ${ }^{2} \mathrm{H}-\mathrm{DMDS}(\mathrm{m} / \mathrm{z} 97$ and $\mathrm{m} / \mathrm{z}$ 100: presence of 3 and 6 deuterium atoms, respectively), whereas later scans revealed mainly $m / z 94$ which is indicative of DMDS (Fig. 2). Similarly, earlier scans of the DMTS peak revealed mostly fragment ions of ${ }^{2} \mathrm{H}-\mathrm{DMTS}(\mathrm{m} / z 129$ and $m / z$ 132: presence of 3 and 6 deuterium atoms, respectively), whereas latter scans showed mostly $m / z 126$ (Fig. 2), which is characteristic of DMTS. To express the relative abundance of ${ }^{2} \mathrm{H}-\mathrm{DMDS}$ and ${ }^{2} \mathrm{H}-\mathrm{DMTS}$ in samples, the ratios of $\mathrm{m} / \mathrm{z}$ 94, 97 and 100 (DMDS), and $\mathrm{m} / \mathrm{z}$ 126, 129 and 132 (DMTS), for each of the second and the center scan of the DMDS and DMTS peaks 
are listed in Table 2. Obviously, $m / z 97$ and 100 (indicative of ${ }^{2} \mathrm{H}$-DMDS), and $m / z 129$ and 132 (indicative of ${ }^{2} \mathrm{H}-\mathrm{DMTS}$ ), are prevalent only when bed bugs metabolized sheep blood enriched with ${ }^{2} \mathrm{H}_{3}$-methionine, particularly the $2.5-\mathrm{mg}$ dose.

When feces extracts of bed bugs that had fed ${ }^{13} \mathrm{C}_{6}$-histidine-enriched sheep blood were analyzed by HPLC-MS, two histamine peaks were detected which were separated by $0.1 \mathrm{~min}$. The first peak comprised protonated (charged) ${ }^{13} \mathrm{C}_{5}$-histamine $\left({ }^{13} \mathrm{C}_{5} \mathrm{H}_{10} \mathrm{~N}_{3}\right)$ with a molecular weight $(\mathrm{M}+6)$ of 117.1043 (replicate 1) and 117.1010 (replicate 2). The second peak comprised protonated histamine $\left(\mathrm{C}_{5} \mathrm{H}_{10} \mathrm{~N}_{3}\right)$ with a molecular weight $(\mathrm{M}+1)$ of 112.0869 (replicate 1$)$ and 112.0846 (replicate 2). The incorporation of five ${ }^{13} \mathrm{C}$ carbon atoms into the histamine pheromone component obviously had increased its molecular weight by 5 Daltons. Relative to histamine, ${ }^{13} \mathrm{C}_{5}$-histamine was present at 3.32\% (replicate 1) and 6.94\% (replicate 2).

To test by NMR spectroscopy for the presence of ${ }^{13} \mathrm{C}$-histamine in feces extracts of bed bugs, a ${ }^{13} \mathrm{C}\left\{{ }^{1} \mathrm{H}\right\}$ reference spectrum of histamine in $\mathrm{CD}_{3} \mathrm{OD}$ was acquired (Fig. $3-\mathrm{a}$ ), and the ${ }^{1} J_{\mathrm{C}-\mathrm{C}}$ scalar coupling $(34.6 \mathrm{~Hz})$ was measured from the natural abundance of ${ }^{13} \mathrm{C}$-satellite peaks. The alpha-carbon $\left(\mathrm{C} \alpha,-\mathrm{CH}_{2} \mathrm{NH}_{2}\right)$ of histamine has a resonance $(\delta=40.55 \mathrm{ppm})$ with additional resonances appearing as a doublet at $\delta=40.55 \mathrm{ppm}\left({ }^{2} J_{\mathrm{CC}}=34.5 \mathrm{~Hz}\right)$ arising from the $1.108 \%$ natural abundance of ${ }^{13} \mathrm{C}$ at $\mathrm{C} \beta$. The ${ }^{13} \mathrm{C}$ NMR spectrum of feces extracts obtained from bed bugs that ingested sheep blood containing no added ${ }^{13} \mathrm{C}$-histidine was not completely diagnostic since many other compounds can have carbon resonances at similar chemical shifts. However, the use of ${ }^{13} \mathrm{C}$ isotopically-enriched histidine allowed us to detect and unambiguously identify the resonances from ${ }^{13} \mathrm{C}$-enriched histamine (Fig. 3-b), and thus to prove conclusively that bed bugs can convert blood-derived histidine into histamine. Furthermore, because the histamine $\mathrm{C} \alpha$ peaks were not obscured by resonances from other compounds in the extract, it was possible to 
measure the molar ratio of ${ }^{13} \mathrm{C}$-labelled to total (labelled + unlabelled) histamine present in feces extracts of bed bugs that ingested ${ }^{13} \mathrm{C}$-histadine-enriched sheep blood. The amount of ${ }^{13} \mathrm{C}$ histamine converted from ${ }^{13} \mathrm{C}$-histidine was calculated as the sum of peak areas of the ${ }^{13} \mathrm{C}-{ }^{13} \mathrm{C}$ doublet, adjusted to account for small contributions from the natural abundance of ${ }^{13} \mathrm{C}$. The amount of ${ }^{12} \mathrm{C}$-histamine was determined using the peak area of the singlet at $\delta=40.55 \mathrm{ppm}$, corrected for the small amount of ${ }^{12} \mathrm{C}$-histidine still present in the $99.9 \%$ uniformly-labelled ${ }^{13} \mathrm{C}$ histidine, and then multiplying it by a factor of 100/1.108. This scaling factor adjusts the peak area observed for the ${ }^{12} \mathrm{C}$-histidine (with ${ }^{13} \mathrm{C}$-histidine present at natural abundance) for the signal intensity enhancement of ${ }^{13} \mathrm{C}$-histidine introduced by the isotopic enrichment, permitting the actual molar ratio to be determined. Using the ratio of these corrected peak areas, the percentage of ${ }^{13} \mathrm{C}$-histamine originating from ${ }^{13} \mathrm{C}$-histidine was found to be $3.3 \%$, in close agreement with the percentage(s) measured by HPLC-MS (see above).

\section{Discussion}

Our GC-MS, HPLC-MS and NMR spectroscopic data together provide strong evidence that bed bugs can produce their volatile pheromone components DMDS and DMTS from methionine, as well as their non-volatile pheromone component histamine from histidine. The ability to produce histamine from histidine via a decarboxylase has previously been reported for diverse taxa including, but not limited to, humans, ${ }^{7}$ locusts, ${ }^{8}$ vinegar flies, ${ }^{13}$ and bacteria. ${ }^{9}$ Although not yet shown experimentally, it is conceivable that also bed bugs produce histamine via the histidine decarboxylase.

Both the ant Paltothyreus tarsatus ${ }^{11,12}$ and bed bugs ${ }^{\text {this study }}$ can produce DMDS and DMTS from labelled methionine, but the exact biosynthetic pathway remains unknown. In humans, 
most methionine metabolism takes place in the liver, ${ }^{14}$ but some methionine is fermented in the colon by microbes. Analogously, microbes dwelling in the digestive tract of bed bugs may contribute to sulfide pheromone biosynthesis. This possibility is supported by recent findings that gut bacteria mediate aggregations of German cockroaches. ${ }^{15}$ The gut bacterial community of German cockroaches emits highly volatile carboxylic acids that, in turn, elicit the aggregation behavior of its insect host. Whether the microbial gut flora of bed bugs is capable of producing the bed bug pheromone components DMDS and DMTS is not yet known, but various microorganisms possess a methionine gamma lyase which degrades L-methionine directly to methanthiol which is then converted to DMDS and DMTS.

Although bed bugs can produce histamine from histidine, this amino acid conversion may, or may not, be the single or primary biosynthetic pathway. Generally, when 100 bed bugs metabolize $1 \mathrm{~mL}$ of human blood, they excrete about $30 \mu \mathrm{g}$ of histamine with their feces (R.G., unpubl. data). Yet, $1 \mathrm{~mL}$ of human blood contains only $11 \mu \mathrm{g}$ of the amino acid precursor histidine. ${ }^{16}$ It follows that even if bed bugs were to decarboxylate all of the histidine in human blood to histamine, they would still produce histamine at an amount well below $30 \mu \mathrm{g}$. The same interpretation pertains to this study, because sheep blood contains only twice as much histidine as human blood. ${ }^{17}$ Although the experimental sheep blood that bed bugs metabolized contained as much ${ }^{13} \mathrm{C}$-histidine $(25 \mu \mathrm{g} / \mathrm{mL})$ as natural histidine, or even 10 -times $(250 \mu \mathrm{g} / \mathrm{mL})$ more ${ }^{13} \mathrm{C}$ histidine, the ratio of ${ }^{13} \mathrm{C}$-histamine to ${ }^{12} \mathrm{C}$-histmine determined by HPLC or NMR analyses ranged between $3: 97$ and 6:94, indicating that only a small proportion of the available ${ }^{13} \mathrm{C}$ histidine was converted to ${ }^{13} \mathrm{C}$-histamine. However, it is still possible that bed bugs sequestered ${ }^{12} \mathrm{C}$-histidine or metabolized ${ }^{12} \mathrm{C}$-histamine from previous feeding bouts on human blood, excreted sequestered ${ }^{12} \mathrm{C}$-histamine in our experiments and thereby biased the ratio of ${ }^{13} \mathrm{C}$ - to 
${ }^{12} \mathrm{C}$-histamine in favour of ${ }^{12} \mathrm{C}$-histamine. This possibility could be tested experimentally by allowing the same cohort of bed bugs to feed repeatedly on ${ }^{13} \mathrm{C}$-histidine-enriched sheep blood, and then by analysing the feces of these bed bugs for sequential changes in the ratio of ${ }^{13} \mathrm{C}$ - to ${ }^{12} \mathrm{C}$-histamine.

Together, our data show that bed bugs can produce histamine from histidine. However, we cannot exclude the possibility that bed bugs produce histamine also though alternative biosynthetic pathways. Whether this possibility also applies to the biosyntheses of DMDS and DMTS from methionine is difficult to ascertain because absolute amounts of these highly volatile components are difficult to quantify in headspace analyses.

In conclusion, we have shown that bed bugs can produce DMDS, DMTS and histamine from amino acid precursors present in sheep and human blood. It is conceivable, however, that bed bugs produce histamine, and possibly also the two sulfides, primarily de novo.

\section{Acknowledgements}

We thank S. Oliver and L. Tu for word processing and comments, S. Takács for some graphical illustrations, and two anonymous reviewers for constructive comments. The study was supported by an NSERC-Discovery Grant to G.G., an NSERC-Industrial Research Chair to G.G. with Scotts Canada Ltd. as the industrial partner, an NSERC-Discovery Grant to R.B., and a Michael Smith Foundation for Health Research Career Investigator Award to R.B.

\section{References}

(1) Weeks, E. N. I.; Birkett, M. A.; Cameron, M. M.; Pickett, J. A.; Logan, J. G. Pest Manage. Sci. 2011, 67, 10. doi:10.1002/ps.2024 
(2) Goddard, J.; de Shazo, R. JAMA J. Am. Med. Assoc.2009, 301, 1358. doi:10.1001/jama.2009.405

(3) Reinhardt, K.; Kempke, D.; Naylor, R. A.; Siva-Jothy, M. T. Med. Vet. Entomol. 2009, 2(2)3, 163. doi:10.1111/j.1365-2915.2008.00793.x.

(4) Boase, C. Sixth International Conference on Urban Pests; OOK-Press Kft: Budapest, Hungary, 2008.

(5) Gries, R.; Britton, R.; Holmes, M., Zhai; H.; Draper, J.;Gries, G. Angew. Chem. Int. Ed. 2015, 54, 1135. doi:10.1002/anie.201409890.

(6) Weatherby, D.; Ferguson, S.; Blood Chemistry and CBC Analysis - Clinical Laboratory Testing From A Functional Perspective 2004.

(7) Schayer, R.W. 1956. The origin and fate of histamine in the body. In: Ciba Foundation Symposium on Histamine; Wolstenholme, G.E.W., O’Connor, C.M., Eds.; John Wiley \& Sons, Ltd.: Chichester, UK, 1956; pp 183-188.

(8) Elias, M. S.; Evans, P. D. J. Neurochem. 1983, 41, 562. doi:10.1111/j.14714159.1983.tb04776.x

(9) Landete, J. M.; De Las Rivas, B.; Marcobal, A.; Munoz, R. 2008. Crit. Rev. Food Sci 2008, 48, 697. doi:10.1080/10408390701639041

(10) Crewe, R. M.; Ross, F. P. Nature 1975, 254: 448. doi:10.1038/254448a0

(11) Crewe, R. M.; Ross, F.P. Insect Biochem. 1975, 5, 839. doi:10.1016/00201790(75)90028-1

(12) Montes, C.; Cuadrillero, C.; Vilella, D. J. Med. Entomol. 2002, 39(4): 675. doi:10.1603/0022-2585-39.4.675

(13) Sarthy, P.V. J. Neurochem. 1991, 57(5), 1757. doi:10.1111/j.1471-4159.1991.tb06378.x 
(14) Finkelstein, J.D. J. Nutr. Biochem. 1990, 1, 228.

(15) Wada-Katsumata, A.; Zurek, L.; Nalyanya, G.; Roelofs, W. L.; Zhang, A.; Schal, C. PNAS, 2015, 112(51), 15678. doi:10.1073/pnas.1504031112

(16) Stein, W.H.; Moore, S. J. Bio. Chem. 1954, 211(2), 915. doi:

(17) Alexander, F. Q. J. Exp. Physiol. CMS 1944, 33, 71-76.

doi:10.1113/expphysiol.1944.sp000897 
1 Table 1. Summary of information related to the feeding of bed bugs on defibrionated sheep blood, enriched with unlabelled or

2 labelled $\left({ }^{2} \mathrm{H}\right)$ methionine, or unlabelled or labelled $\left({ }^{13} \mathrm{C}\right)$ histamine (see Fig. 1).

3

\begin{tabular}{|c|c|c|c|c|c|c|c|}
\hline \multirow[b]{2}{*}{ Rep. \# } & \multirow[b]{2}{*}{$\begin{array}{l}\text { Volume }(\mathrm{mL}) \text { of } \\
\text { blood offered }\end{array}$} & \multicolumn{4}{|c|}{ Amount (mg) of precursor added to blood } & \multirow[b]{2}{*}{$\begin{array}{l}\text { Number } \& \text { sex of bed } \\
\text { bugs offered blood }\end{array}$} & \multirow[b]{2}{*}{$\begin{array}{l}\text { Number (\%) } \\
\text { feeding }\end{array}$} \\
\hline & & methionine & ${ }^{2} \mathrm{H}$-methionine & histamine & ${ }^{13}$ C-histamine & & \\
\hline 1 & 5 & 0 & 0 & 0 & 0 & 100 males & $96(96)$ \\
\hline 2 & 5 & 2.5 & 0 & 0 & 0 & 100 males & $76(76)$ \\
\hline 3 & 5 & 0 & 0.25 & 0 & 0 & 100 males & $56(56)$ \\
\hline 4 & 5 & 0 & 2.5 & 0 & 0 & 100 males & $49(49)$ \\
\hline 5 & 5 & 0 & 2.5 & 0 & 0 & 100 males & $63(63)$ \\
\hline 6 & 10 & 0 & 0 & 0 & 0 & 100 males/females & $25(25)$ \\
\hline 7 & 10 & 0 & 0 & 5 & 0 & 100 males/ females & $58(58)$ \\
\hline 8 & 10 & 0 & 0 & 0 & 5 & 600 males/females & $241(40)$ \\
\hline 9 & 10 & 0 & 0 & 0 & 5 & 600 males/females & $271(45)$ \\
\hline
\end{tabular}


4 Table 2. Mass spectral data indicating biosyntheses of dimethyl disulfide (DMDS) and dimethyl

5 trisulfide (DMTS) from defibrinated sheep blood (SB) enriched with unlabelled or labelled $\left({ }^{2} \mathrm{H}\right)$

6 methionine. Note the \% increase of fragmentation ions indicative of deuterium presence $(\mathrm{m} / z 97$

7 and 100 for DMDS; $m / z 129$ and 132 for DMTS) in replicates (Rep.) 3, 4 and 5, when bed bugs

8 metabolized sheep blood enriched with ${ }^{2} \mathrm{H}$-methionine.

\begin{tabular}{|c|c|c|c|c|}
\hline \multicolumn{5}{|c|}{ Dimethyl disulfide } \\
\hline Rep. \# & Treatments & $\begin{array}{l}\text { GC peak area } \\
\text { (counts) }\end{array}$ & $\begin{array}{l}2^{\text {nd }} \text { scan of GC peak } \\
m / z 94 / 97 / 100(\%)\end{array}$ & $\begin{array}{l}\text { Centre scan of GC peak } \\
m / z \text { 94/97/100 (\%) }\end{array}$ \\
\hline 1 & SB & 800149 & $30 / 5 / 0.15$ & $100 / 5 / 0$ \\
\hline 2 & $\mathrm{SB}+$ methionine $(2.5 \mathrm{mg})$ & 111700 & $100 / 1.5 / 0$ & $100 / 0.7 / 0$ \\
\hline 3 & $\mathrm{SB}+{ }^{2} \mathrm{H}$-methionine $(0.25 \mathrm{mg})$ & 638917 & $70 / 80 / 2$ & $100 / 3 / 0$ \\
\hline 4 & $\mathrm{SB}+{ }^{2} \mathrm{H}$-methionine (2.5 mg) & 3888000 & $0 / 25 / 100$ & $100 / 80 / 25$ \\
\hline 5 & $\mathrm{SB}+{ }^{2} \mathrm{H}$-methionine (2.5 mg) & 638346 & $100 / 45 / 5$ & $100 / 15 / 0.5$ \\
\hline \multicolumn{5}{|c|}{ Dimethyl trisulfide } \\
\hline Rep. \# & Treatments & $\begin{array}{l}\text { GC peak area } \\
\text { (counts) }\end{array}$ & $\begin{array}{l}2^{\text {nd }} \text { scan of GC peak } \\
m / z 94 / 97 / 100(\%)\end{array}$ & $\begin{array}{l}\text { Centre scan of GC peak } \\
m / z \text { 94/97/100 (\%) }\end{array}$ \\
\hline 1 & SB & 45038 & $100 / 1.5 / 0$ & $100 / 1 / 0$ \\
\hline 2 & $\mathrm{SB}+$ methionine $(2.5 \mathrm{mg})$ & 87155 & $100 / 1.5 / 0$ & $100 / 0.4 / 0$ \\
\hline 3 & $\mathrm{SB}+{ }^{2} \mathrm{H}$-methionine $(0.25 \mathrm{mg})$ & 120049 & $100 / 1.5 / 0.75$ & $100 / 0 / 0.35$ \\
\hline 4 & $\mathrm{SB}+{ }^{2} \mathrm{H}$-methionine (2.5 mg) & 321059 & $1 / 100 / 15$ & $100 / 25 / 0.2$ \\
\hline 5 & $\mathrm{SB}+{ }^{2} \mathrm{H}$-methionine $(2.5 \mathrm{mg})$ & 115473 & $35 / 100 / 1$ & $100 / 4 / 0$ \\
\hline
\end{tabular}


16

13 Figure captions

14

15

16

17

18

19

20

21

22

23

24

25

26

27 atoms being ${ }^{13} \mathrm{C}$ rather than ${ }^{12} \mathrm{C}$ ). 

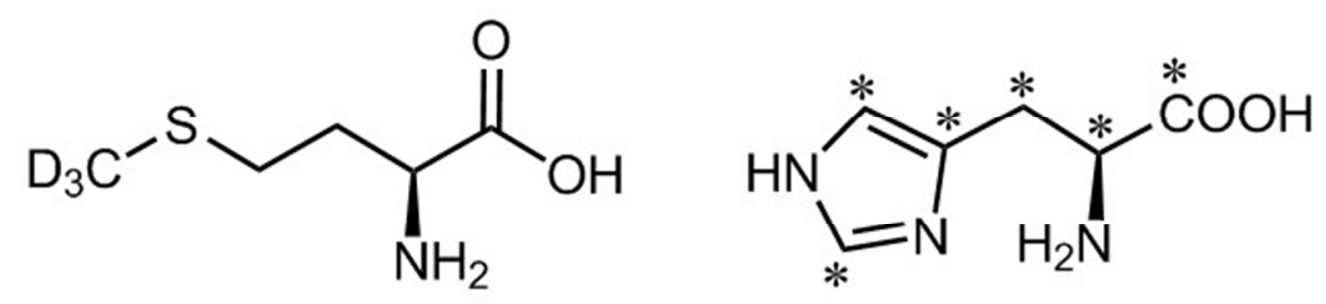

$168 \times 41 \mathrm{~mm}(96 \times 96 \mathrm{DPI})$ 

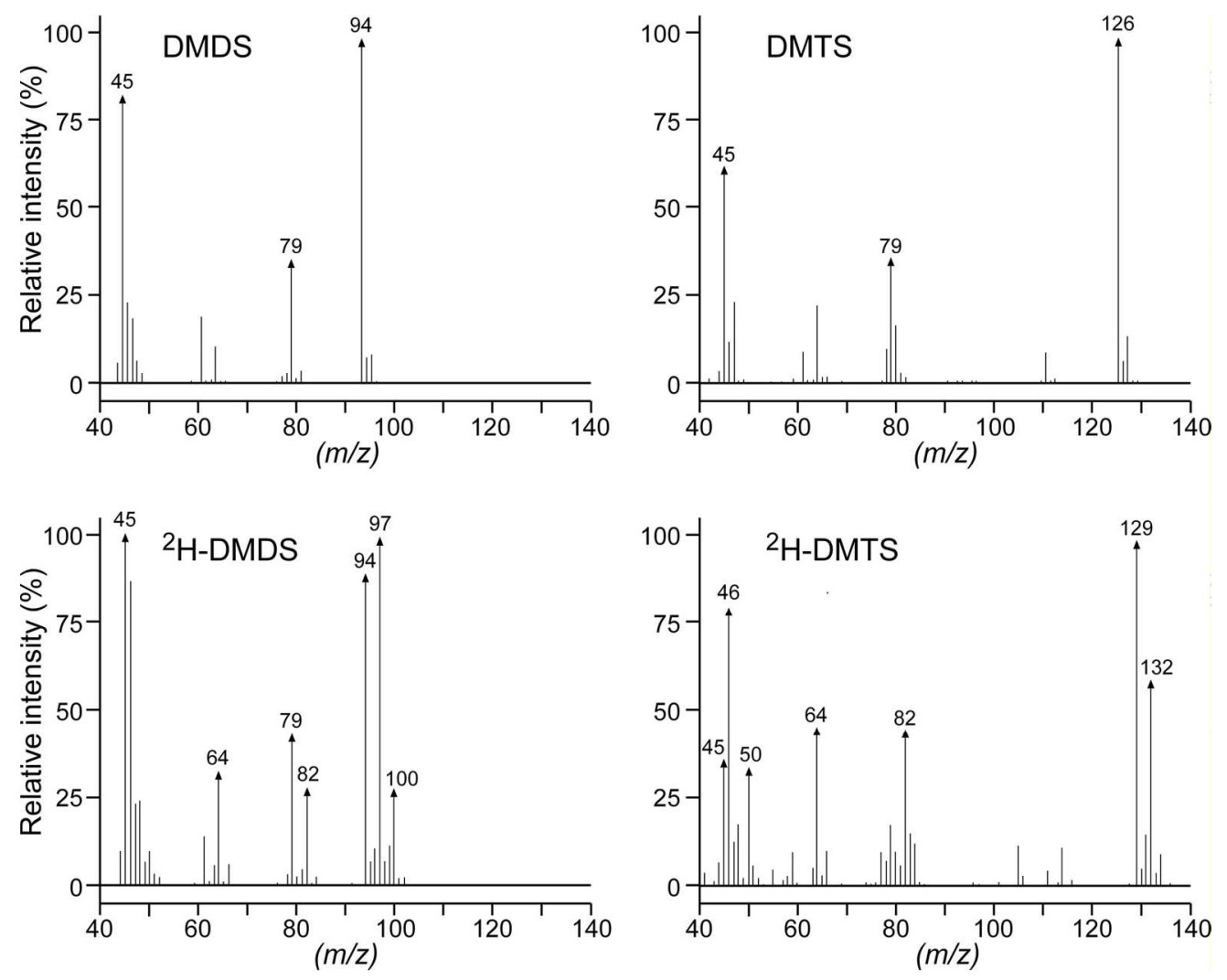

$164 \times 132 \mathrm{~mm}(300 \times 300 \mathrm{DPI})$ 


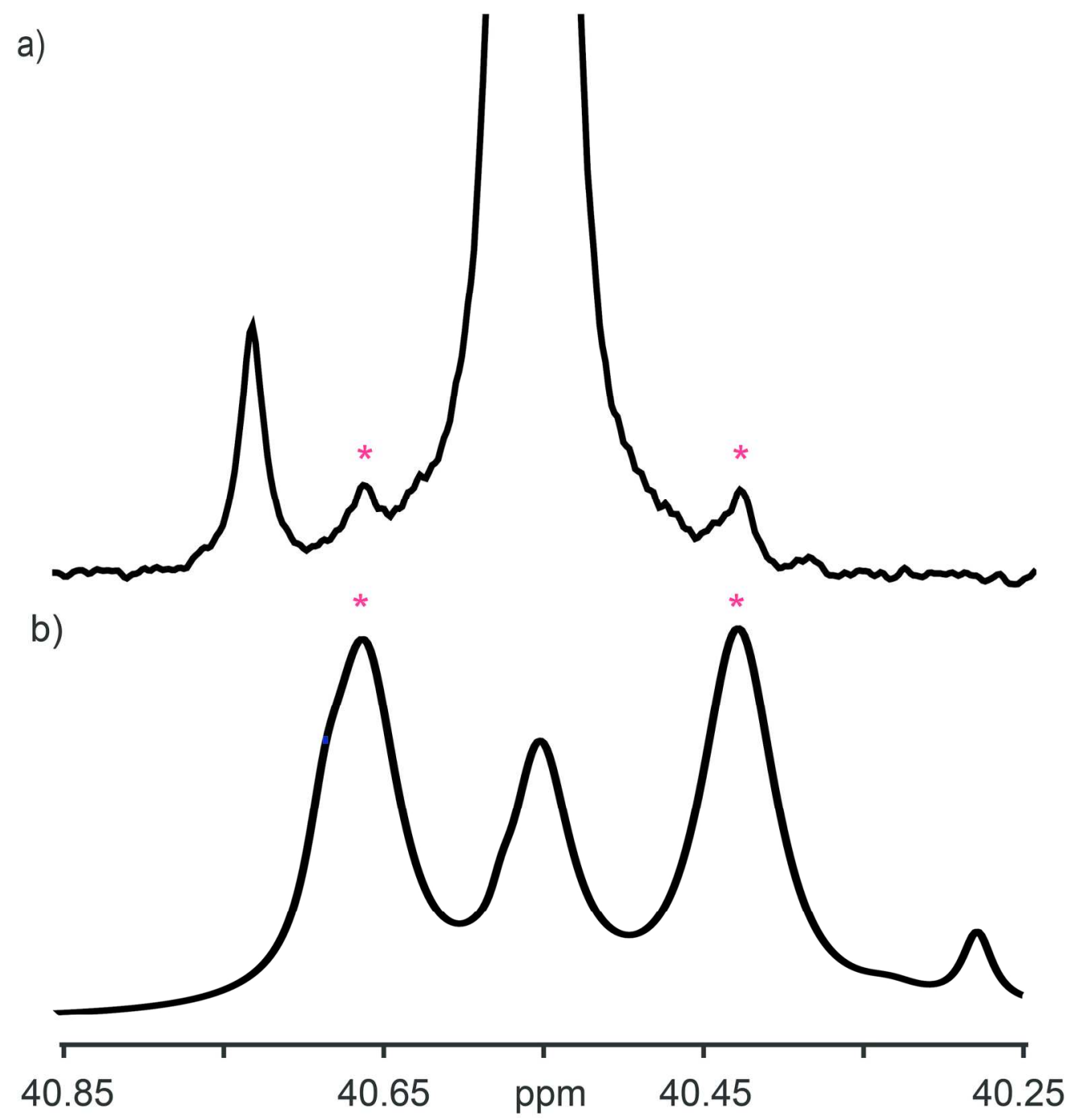

Figure 3

$86 \times 93 \mathrm{~mm}(600 \times 600$ DPI $)$ 